\title{
Taxonomical Investigation on Some Species of Genus Allium Based on the Pollen Morphology
}

\author{
Mehdi Heidarian ${ }^{1}$, Seyed Mohammad Mehdi Hamdi ${ }^{{ }^{*}}$, \\ Mohammad Mehdi Dehshiri ${ }^{3}$, Taher Nejadsattari ${ }^{1}$ \\ and Seyed Mohammad Masoumi ${ }^{4}$
}

${ }^{1}$ Department of Biology, Science and Research Branch, Islamic Azad University, Tehran, Iran.

${ }^{2}$ Department of Biology, Central Tehran Branch, Islamic Azad University, Tehran, Iran.

${ }^{3}$ Department of Biology, Borujerd Branch, Islamic Azad University, Borujerd, Iran. ${ }^{4}$ Department of Biology, Razi University, Kermanshah, Iran.

\begin{abstract}
Authors' contributions
This work was carried out in collaboration among all authors. All authors read and approved the final manuscript.

Article Information

DOI: 10.9734/ARRB/2019/v32i630103

Editor(s):

(1) Dr. Jin-Zhi Zhang, Key Laboratory of Horticultural Plant Biology (Ministry of Education), College of Horticulture and Forestry Science, Huazhong Agricultural University, China. (2) Dr. Xiao-Xin Yan, Professor, Department of Anatomy and Neurobiology, Central South University Xiangya School of Medicine (CSU-XYSM), China. Reviewers:

(1) Wilton Mbinda, Pwani University, Kenya. (2) Koudegnan Comlan Mawussi, University of Lome, Togo. (3) Francisco de Assis Ribeiro dos Santos, State University of Feira de Santana, Brazil. Complete Peer review History: http://www.sdiarticle3.com/review-history/50410
\end{abstract}

Original Research Article

Received 02 June 2019

Accepted 09 August 2019

Published 29 August 2019

\begin{abstract}
Aims: The aim of this research was to investigate the morphological characteristics of the pollen grain of some species of genus Allium.

Methodology: The pollen grains were examined by using Light Microscopy (LM), Scanning Electron Microscopy (SEM) and the pollen grains of one species under Transmission Electron Microscopy (TEM).

Results: The pollen grains were oblate and medium in shape and size. The pollen ornamentation of exine surface, exine ornamentation on sulcus edge, lumina number in the exine surface and the state of pollen grain apex in the examined species were different. Semitectate and columellate ectexine with discontinuous endexine were seen in the pollen wall structure (sporoderm). The dendrogram obtained from the pollen characters in SEM observations by using the numerical taxonomy system (NTSYS) software placed the studied species in two types.
\end{abstract}


Conclusion: Our palynological dendrogram can be used for segregation the sections and subgenera taxonomical levels in the studied species of genus Allium and confirmed the phylogram of the recent phylogenetic research.

Keywords: Allium; Amaryllidaceae; monocotyledons; palynology; phylogeny; taxonomy.

\section{INTRODUCTION}

Allium is a member of the family Amaryllidaceae. This genus is one of the largest monocotyledons with a wide dispersion in central and south-east Asia, where the species of this genus constitute a great part of herbaceous societies [1,2]. Approximately, fifty species of this genus are planted extensive or local level that economically have great importance. Some of the wild species of this genus are used as edible, medicinal and even decorative plants. Moreover, the wild species of this genus have valuable potential for supplying of human consuming [3].

The taxonomical position of Allium as the polymorph genus is sophisticated [4,5]. Lately, the phylogenetic examination on this genus has been done on the endemic species on China [1] and confirmed monophyly in Allium by using the phylogenetic analysis of molecular data (ITS nuclear marker and rps16 chloroplast marker); but, the obtained phylogram from the phylogenetic analysis wasn't confirmed for some subgenera. In their research, three main monophyletic groups were specified: the first clade includes subgenera Nectaroscordum, Amerallium and Microscordum; the second clade includes subgenera Caloscordum, Anguinum, Vvedenskya, Porphyroprason and Melanocrommyum and the third clade includes subgenera Butomissa, Cyathophora, Rhizirideum, Allium, Reticulatobulbosa and Polyprason [1].

The palynological studies of genus Allium from some researches are valuable to classify taxonomical level. Majority of these studies were investigated the following characters: exine ornamentation to specify position of the tribe Allieae [6,7], being single sulcus and having extensive sulcus as a predominant morphological pollen character in the genus Allium is determined [8]. The species belong to sections Codonoprasum and Allium were examined and specified the homogeneity of sulcus and pollen grain ornamentation in the genus Allium. Moreover, they indicated that some morphological characters of the pollen grain such as sulcus and presence or lack of operculum that have taxonomic importance in the section level [9]. The pollen grain morphology in some species of Allium (twenty three species in six sections including Molium, Scorodon, Brevispatha, Codonoprasum, Allium and Melanocrommyum) were examined and characterized the shape of pollen grains was prolate and subprolate. Also, in all species extensive sulcus and the smallest and largest pollen grains are belonged to $A$. guttatum Steven. (section Allium) and $A$. roseum $\mathrm{L}$. (section Molium), respectively [2]. Palynological investigation had done in 30 Allium taxa belonging to 15 sections in Iran and the pollen grains were heteropolar, peroblate to suboblate shape, rugulate to microrugulate, perforate to striate in subgenus Melanocrommyum and striate exine ornamentation [10]. According to result of [11], the sulcus was observed in section Allium that this character wasn't observed in the other sections. An extensive sulcus from the beginning to the end of the pollen grains were observed in all taxa in sections of Rhizirideum, Codonoprasum and Allium. In ultrastructure wall of the pollen grains, the exine semitectate and simplicolumellate were observed in all investigated sections [12]. In addition, the exine ornamentation in these sections and related species were heterogeneous and weren't synchronize in classification of these sections and three exine ornamentation including striateperforate, striate-rugulate-perforate and rugulateperforate were observed in these species [12]. They also stated that availability of operculum as an apomorphic character and narrow endexine layer as a taxonomic character in the genus Allium determined in the sections of Rhizirideum, Codonoprasum and Allium [12]. A. ursinum were separated in subspecies level based on the exine ornamentation and stated that this character is an appropriate taxonomic character (granulaterugulate, rugulate-striate ornamentation in the subspecies Ucrainicum and perforate-rugulate ornamentation in the subspecies Ursinum) [13]. Three types of pollen grains in seven subgenera and thirteen sections of Allium were examined in Pakistan that weren't in agreement with the mentioned classifications and determined the types of $A$. fedtschenkoanum (reticulate ornamentation), $A$. grifthianum (rugulatefoveolate ornamentation) and $A$. roylei 
(subpsilate ornamentation) [14]. Characteristics of the pollen grain including qualitative and quantitative characters were demonstrated in some European species of genus Allium including three subgenera (Allium, Amerallium and Rhizirideum) and five sections that explicitly being synchronize with the section taxonomy level [13].

The main aim of our research was to evaluate the pollen morphology and its implications on the taxonomy and phylogeny of some species of the genus Allium.

\section{MATERIALS AND METHODS}

The pollen grains were provided from the collected samples of Komarov Botanical Institute (LE), Moscow, Russia. Samples were collected since May and June 2003 and identified by $E$. Kalikov (Table 1). Also, taxonomic relationships among the studied species in this research showed in Table 1 [1]. For Light Microscopy analysis (LM), the pollen grains were acetolyzed based on Erdtman's method [15]. Then, mounted preparations with glycerine. Thirty pollen grains were measured by Leitz Light Microscopy (HMLUX3) from each studied species and images were taken by Dino camera (AM-423). For Scanning Electron Microscopy analysis (SEM), non-acetolyzed pollen grains were put on metal stubs and transferred to the EMITECH sputter coater for coating by gold-paladium (K450X). Finally, the obtained micrographs were taken by VEGA-TESCAN Scanning Electron Microscopy. For Transmission Electron Microscopy (TEM) preparation, the pollen grains were fixed by $2 \%$ osmium tetroxide and stained by uranylacetate solution [16]. Then, dehydrated in ethanol series and were put in acetone. Finally, embedded in Epon mixture (Epon 812, Epon Harter DDSA, Epon Harter MNA) according to the standard method of [17]. Ultrathin sections of the pollen grains were obtained by an ultramicrotome (LKB 8800 ), then stained with lead citrate (LKB 8800, Ultratome III) [16]. The micrographs were made by using a JEOL-JEM-100B Transmission Electron Microscopy. The terminology used for describing pollen grain characters follows [18, 19,20]. For construction the dendrogram, the obtained characters by SEM observations from the pollen grains were coded (Table 4). Finally, the NTSYS software was used along based on Single Linkage method and UN1 similarity coefficient (binary coefficient) (Table 5) [21].

\section{RESULTS AND DISCUSSION}

The pollen grains in the studied species were observed oblate in shape and medium in size (Table 2 and Fig. 1). In SEM micrographs, the pollen grain characters were different in these species (Table 3, Figs. 2 and 3 ). The exine ornamentation on surface and the exine ornamentation on sulcus edge were different and these characters for each species are expressed as follows: Striate exine ornamentation on surface and sulcus edge for $A$. altissimum, perforate-striate exine ornamentation on surface and perforate on sulcus edge for $A$. fetisowii, striate-perforate exine ornamentation on surface and striate on sulcus edge for $A$. backhousianum, exine ornamentation on surface
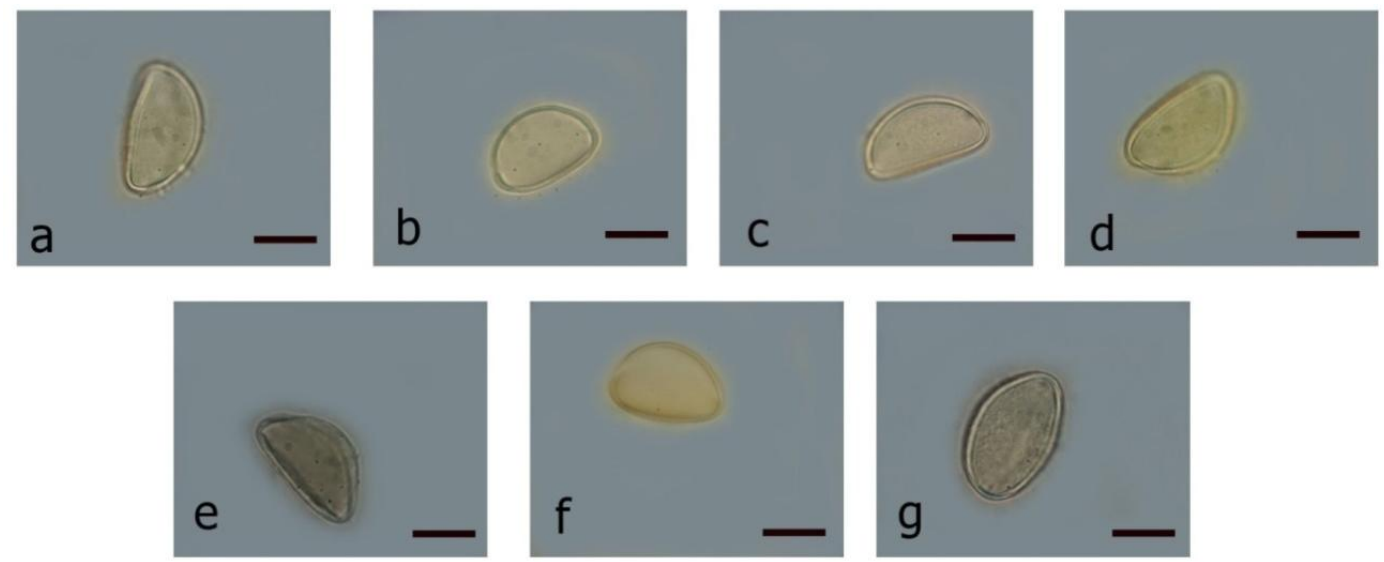

Fig. 1. Pollen grains of the studied species of Allium (Amaryllidaceae), seen on LM: a. A. altissimum, b. A. fetisowii, c. A. backhousianum, d. A. karataviense, e. A. obliquum, f. A. rosenbachianum, g. A. schoenoprasum var. sibiricum. (Light Microscopy, 1000X, scale: $10 \mu \mathrm{m})$ 
Table 1. Taxonomic relationships and collecting data from the studied species of Allium (Amaryllidaceae) [1]

\begin{tabular}{|c|c|c|c|}
\hline Taxon & Section & Subgenus & Collector and detector, date of collecting and herbarium name \\
\hline Allium altissimum Regel. & Procerallium & Melanocrommyum & E. Kalikov, 30.5.2003, gathering from LE \\
\hline Allium fetisowii Regel. & Longibidentata & Melanocrommyum & E. Kalikov, 30.5.2003, gathering from LE \\
\hline Allium backhousianum Regel. & Acmepetala & Melanocrommyum & E. Kalikov, 10.6.2003, gathering from LE \\
\hline Allium karataviense Regel. & Miniprason & Melanocrommyum & E. Kalikov, 30.5.2003, gathering from LE \\
\hline Allium obliquum $\mathrm{L}$. & Oreiprason & Polyprason & E. Kalikov, 30.5.2003, gathering from LE \\
\hline Allium rosenbachianum Regel. & Megaloprason & Melanocrommyum & E. Kalikov, 30.5.2003, gathering from LE \\
\hline Allium schoenoprasum L. & Schoenoprasum & Cepa & E. Kalikov, 30.5.2003, gathering from LE \\
\hline
\end{tabular}

Table 2. Pollen measurements of the studied species of Allium (Amaryllidaceae)

\begin{tabular}{|c|c|c|c|c|c|}
\hline Taxon & $\begin{array}{l}\text { Polar axis }(\mu \mathrm{m}) \\
\text { Min-Mean } \pm S D-M a x\end{array}$ & $\begin{array}{l}\text { Equatorial axis }(\mu \mathrm{m}) \\
\text { Min-Mean } \pm S D-M a x\end{array}$ & P.E & Pollen shape & Pollen type size \\
\hline A. altissimum & $17.00-18.28 \pm 1.24-21.00$ & $27.50-35.18 \pm 6.52-46.00$ & 0.5 & Oblate & Medium \\
\hline A. fetisowii & $15.00-16.16 \pm 1.51-20.00$ & $22.50-30.74 \pm 5.13-37.50$ & 0.5 & Oblate & Medium \\
\hline A. backhousianum & $12.00-16.22 \pm 1.79-17.50$ & $27.50-29.97 \pm 2.34-35.00$ & 0.5 & Oblate & Medium \\
\hline A. karataviense & $12.00-16.84 \pm 2.03-20.00$ & $22.50-31.39 \pm 4.92-41.00$ & 0.5 & Oblate & Medium \\
\hline A. obliquum & $12.50-16.16 \pm 1.60-20.00$ & $25.00-31.56 \pm 6.09-41.00$ & 0.5 & Oblate & Medium \\
\hline A. rosenbachianum & $14.00-19.60 \pm 3.63-25.00$ & $30.00-33.70 \pm 1.92-37.50$ & 0.6 & Oblate & Medium \\
\hline A. schoenoprasum var. sibiricum & $15.00-16.46 \pm 2.24-20.00$ & $25.00-30.82 \pm 5.08-39.00$ & 0.5 & Oblate & Medium \\
\hline
\end{tabular}

Table 3. Pollen data of the studied species of Allium (Amaryllidaceae) from the scanning electron microscopy

\begin{tabular}{|c|c|c|c|c|c|c|}
\hline Taxon & Exorn & Sd & $\mathbf{S}$ & $\mathbf{L}$ & $\mathbf{M}$ & $\mathbf{P}$ \\
\hline A. altissimum & Striate & Striate & Obtuse & $0.06-0.13$ & $0.13-3.46$ & 4 \\
\hline A. fetisowii & Perforate-striate & Perforate & Acute & $0.06-0.20$ & $0.13-0.86$ & 30 \\
\hline A. backhousianum & Striate-perforate & Striate & Obtuse & $0.06-0.13$ & $0.13-0.40$ & 31 \\
\hline A. karataviense & Macrostriate-perforate & Macrostriate-perforate & Obtuse & $0.06-0.13$ & $0.06-0.40$ & 12 \\
\hline A. obliquum & Striate-psilate & Psilate-striate & Obtuse & - & - & - \\
\hline A. rosenbachianum & Perforate-striate & Psilate & Obtuse & $0.06-0.26$ & $0.06-1.20$ & 27 \\
\hline A. schoenoprasum var. sibiricum & Perforate-microstriate & Perforate-microstriate & Acute & $0.06-0.40$ & $0.06-1.60$ & 22 \\
\hline
\end{tabular}

Exorn: Exine ornamentation, Sd: Sulcus edge ornamentation, S: The state of pollen grain apex, L: Lumina size, M: Muri width size, P: The lumina number on the exine surface 
Table 4. The pollen traits from scanning electron microscopy and coding of these characters by the analysis with NTSYS software

\begin{tabular}{|c|c|c|c|c|c|c|}
\hline Taxon & Exorn (code) & Sd (code) & S (code) & $L$ (code) & $M$ (code) & $P$ (code) \\
\hline A. altissimum & Striate (1) & Striate (1) & Obtuse (1) & $0.06(1)-0.13(1)$ & $0.13(1)-3.46(5)$ & $4(1)$ \\
\hline A. fetisowii & Perforate-striate (2) & Perforate (2) & Acute (2) & $0.06(1)-0.20(2)$ & $0.13(1)-0.86(2)$ & $30(5)$ \\
\hline A. backhousianum & Striate-perforate (3) & Striate (1) & Obtuse (1) & $0.06(1)-0.13(1)$ & $0.13(1)-0.40(1)$ & $31(6)$ \\
\hline A. karataviense & Macrostriate-perforate (4) & Macrostriate-perforate (3) & Obtuse (1) & $0.06(1)-0.13$ (1) & $0.06(2)-0.40(1)$ & $12(2)$ \\
\hline A. obliquum & Striate-psilate (5) & Psilate-striate (4) & Obtuse (1) & $(0)$ & 0 & 0 \\
\hline A. rosenbachianum & Perforate-striate (2) & Psilate (5) & Obtuse (1) & $0.06(1)-0.26(3)$ & $0.06(2)-1.20(3)$ & $27(4)$ \\
\hline $\begin{array}{l}\text { A. schoenoprasum } \\
\text { var. sibiricum }\end{array}$ & Perforate-microstriate (6) & Perforate-microstriate (6) & Acute (2) & $0.06(1)-0.40(4)$ & $0.06(2)-1.60(4)$ & $22(3)$ \\
\hline
\end{tabular}

Table 5. The similarity coefficients of the studied species of Allium (Amaryllidaceae) compared with the others by using the NTSYS software

\begin{tabular}{llllll}
\hline Taxon & $\mathbf{a}$ & $\mathbf{b}$ & $\mathbf{c}$ & $\mathbf{d}$ & $\mathbf{e}$ \\
\hline $\mathrm{a}$ & 1.00 & & & & \\
$\mathrm{~b}$ & 0.40 & 1.000 & & & \\
$\mathrm{c}$ & 0.76 & 0.40 & 1.00 & & \\
$\mathrm{~d}$ & 0.54 & 0.222 & 0.66 & 1.00 & 1.00 \\
$\mathrm{e}$ & 0.22 & 0.00 & 0.22 & 0.22 & 0.22 \\
$\mathrm{f}$ & 0.40 & 0.400 & 0.40 & 0.54 & 0.00 \\
$\mathrm{~g}$ & 0.22 & 0.40 & 0.22 & 0.40 & 0.40 \\
\hline \multicolumn{7}{r}{} & a. A. altissimum, b. A. fetisowii, c. A. backhousianum, d. A. karataviense, e. A. obliquum, f. A. rosenbachianum, g. A. schoenoprasum var. sibiricum
\end{tabular}

a. A. altissimum, b. A. fetisowii, c. A. backhousianum, d. A. karataviense, e. A. obliquum, f. A. rosenbachianum, g. A. schoenoprasum var. sibiricum 
and sulcus edge of macrostriate for $A$. karataviense, striate-psilate exine ornamentation on surface and psilate-striate exine ornamentation on sulcus edge for $A$. obliquum, perforatestriate exine ornamentation on surface and psilate exine ornamentation on sulcus edge for A. rosenbachianum, perforate-microstriate exine ornamentation on surface and sulcus edge for $A$. schoenoprasum (Table 3 ). The pollen grains of $A$. fetisowii and $A$. schoenoprasum species were acute in the end and in the other species were obtuse (Table 3 ). The size of lumina and muri in the studied species also was different. Lumina's size almost was observed similar in $A$. altissimum, $A$. backhousianum and $A$. karataviense (0.06- $0.13 \mu \mathrm{m})$ (Table 3 ). The number of exine surface lumina, was the least (4 lumina per $2 \mu \mathrm{m}^{2}$ ) for $A$. altissimum and the most (30 and 31 lumina per $2 \mu \mathrm{m}^{2}$ ) for $A$. fetisowii and $A$. backhousianum species, respectively (Table 3).
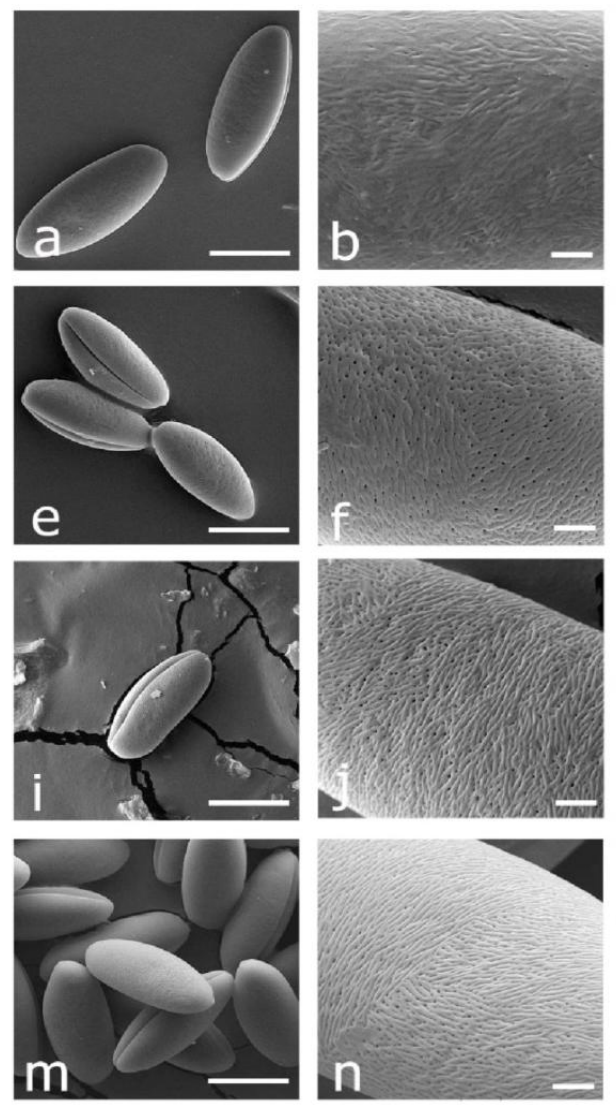

The palynological dendrogram were placed these taxa in two types: type one including subgenus Melanocrommyum and Сepa and the other types including subgenus Polyprason (Fig. 5).

This research indicated that there were no differences in pollen shape and pollen size characters; but, the dendrogram of pollen characters from SEM observations provided useful valuable taxonomical characters on the subgenera and sections classifications (Tables 4 \& 5, Fig. 5).

Various shapes of pollen grains were observed in Allium spp. on previous investigations and the main shape of the pollen grains in this genus is oblate shape. Medium pollen type was observed in the most species studied here and previous research $[2,9,10,11,22,14,13]$.
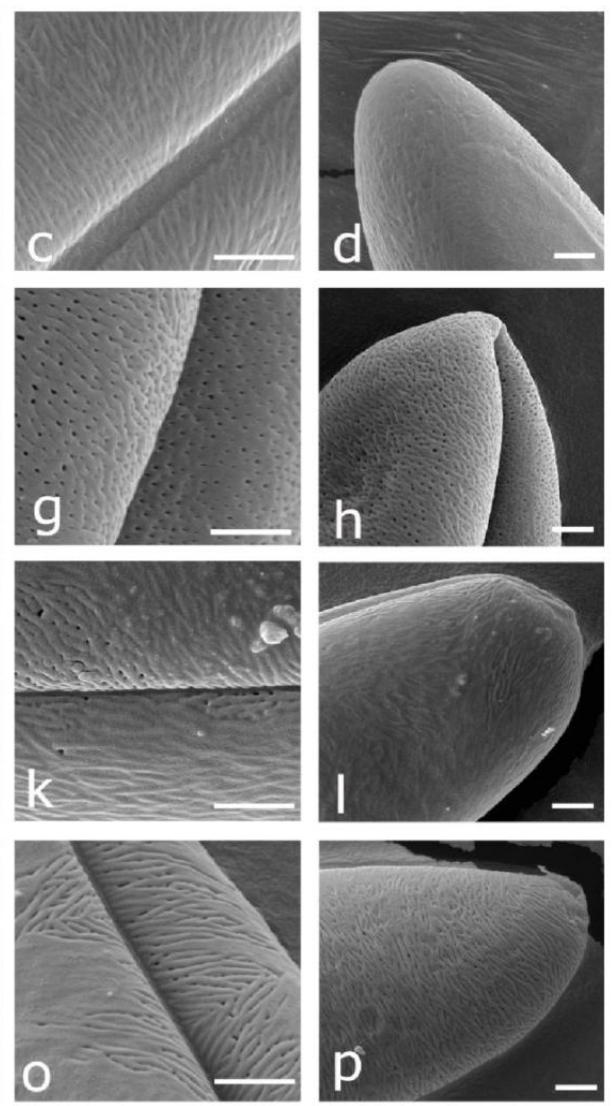

Fig. 2. Pollen grains of the studied species of Allium (Amaryllidaceae), on SEM: (for each species, the equatorial view of pollen grain, exine ornamentation, sulcus edge exine ornamentation and the state of pollen grain apex have been determined, respectively). $A$. altissimum (a-d), A. fetisowii (e-h), A. backhousianum (i-l) and A. karataviense (m-p). (Scale bar: $20 \mu \mathrm{m}$ for a, e, i \& m., scale bar: $2 \mu \mathrm{m}$ for b, c, d, f, g, h, j, k, l, n, o \& p.) 

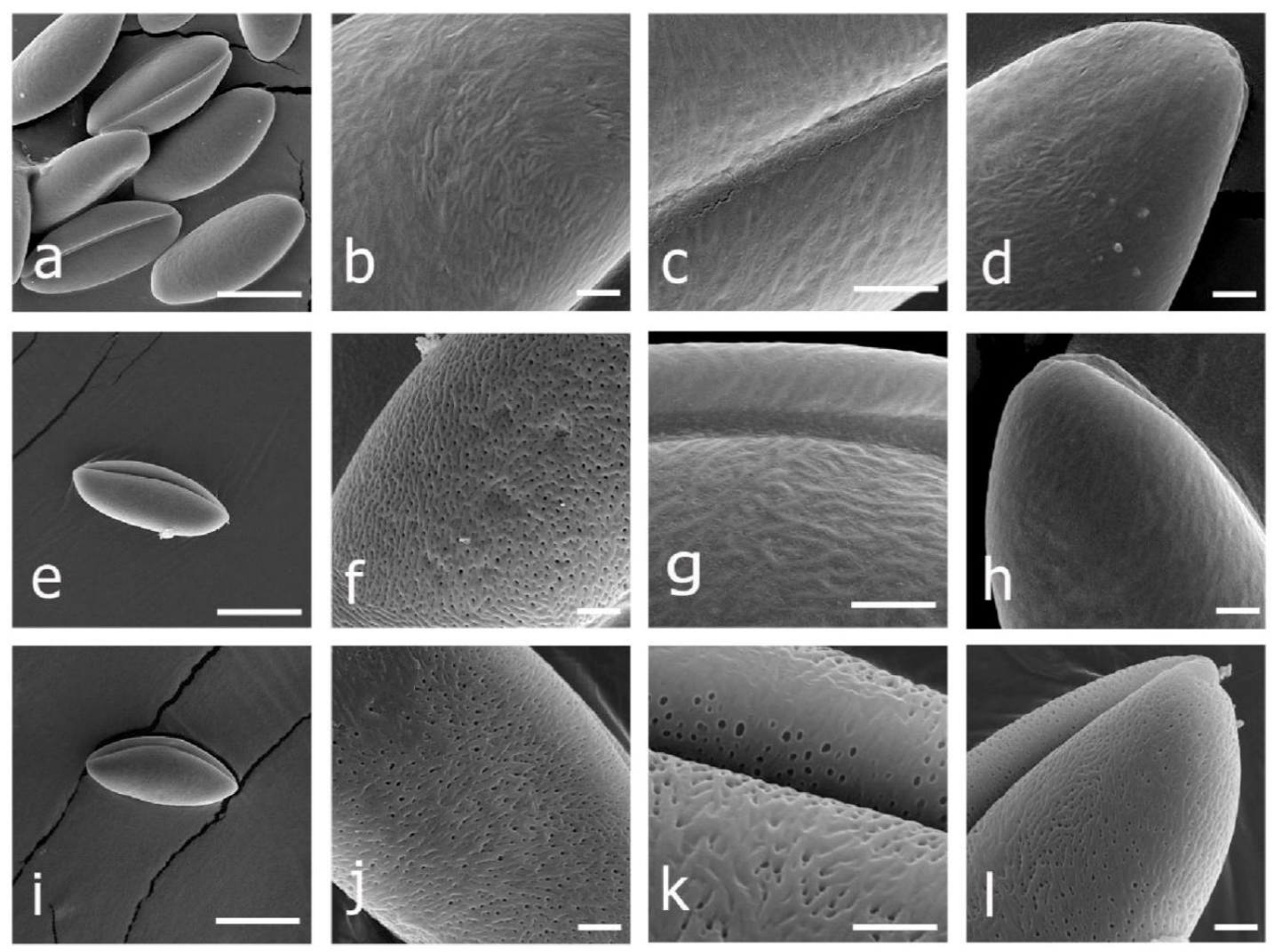

Fig. 3. Pollen grains of the studied species of Allium (Amaryllidaceae), on SEM: (for each species, the equatorial view of pollen grain, exine ornamentation, sulcus edge exine ornamentation and the state of pollen grain apex have been determined, respectively). $A$. obliquum (a-d), A. rosenbachianum (e-h) and A. schoenoprasum var. sibiricum (i-l). (Scale bar: $20 \mu \mathrm{m}$ for a, e \& i., scale bar: $2 \mu \mathrm{m}$ for b, c, d, f, g, h, j, k \& l)

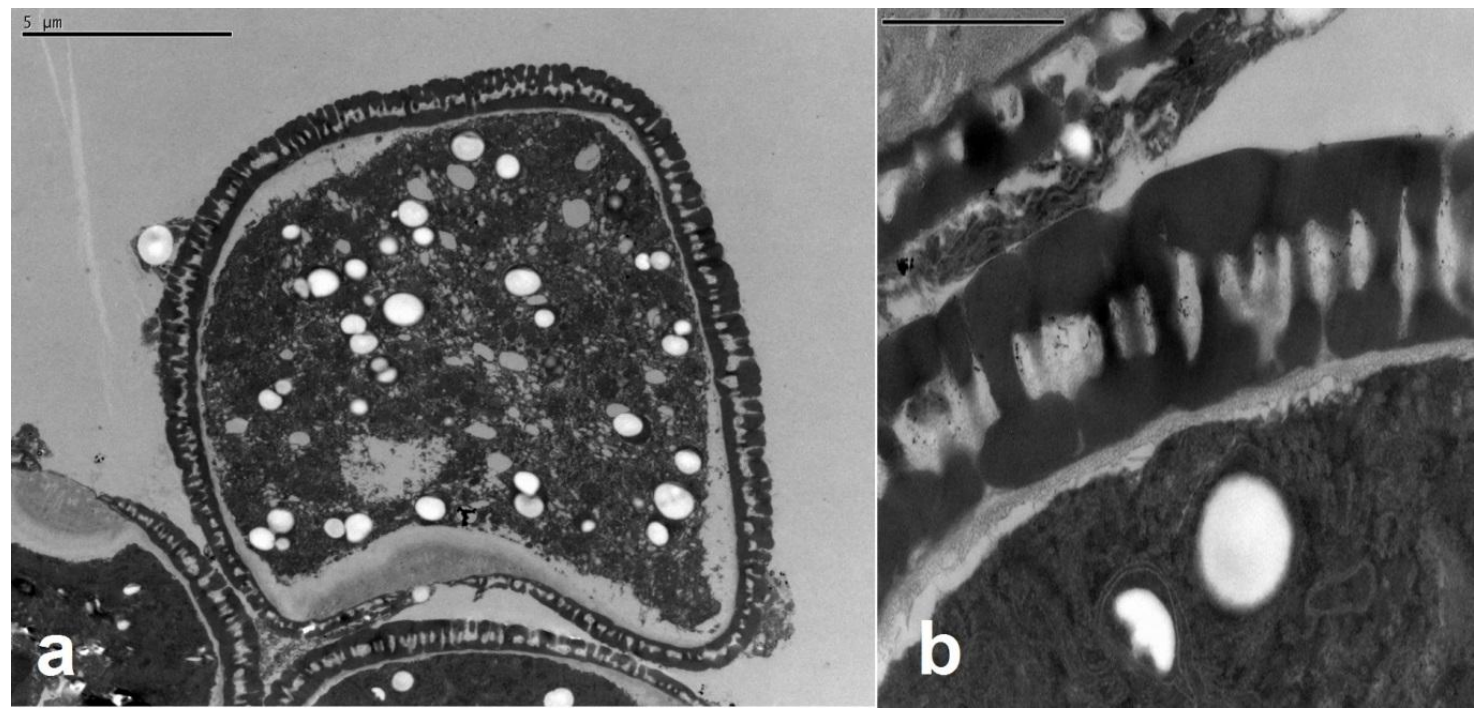

Fig. 4. Ultra-thin section on pollen grain of $A$. schoenoprasum var. sibiricum (Amaryllidaceae): a. pollen grain (Scale bar: $5 \mu \mathrm{m}$ ), b: exine structure (Scale bar: $1 \mu \mathrm{m})$ 


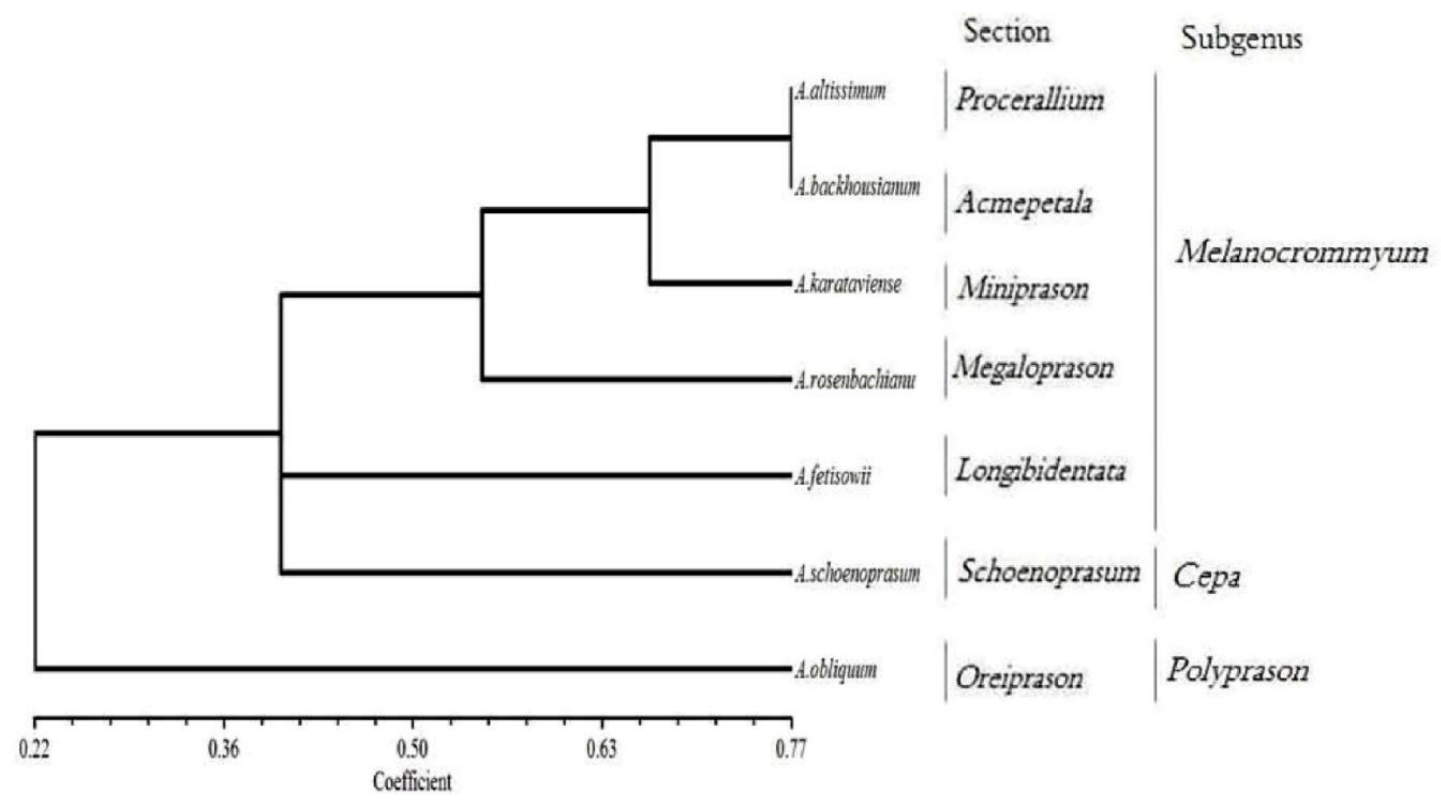

Fig. 5. Dendrogram obtained from implication of pollen morphology on taxonomic relationships of the studied species of Allium (Amaryllidaceae)

The results of $A$. schoenoprasum TEM micrographs belongs to section Schoenoprasum and subgenus Cepa revealed that the ectexine is semitectate, infratectum is simplicolumellate, foot-layer is discontinuous and endexine layer is very thin and discontinuous (Fig. 4). Our research on the genus Allium confirms previous palynological research on pollen wall structure on Codonoprasum, Allium and Rhizirideum sections $[9,12]$.

The perforate-striate exine surface ornamentation for two species including $A$. fetisowii and $A$. rosenbachianum belong to the subgenus Melanocrommyum was alike; but, these two species were different in the exine ornamentation on sulcus edge, the number of exine surface lumina, the state of pollen grain apex and the size of lumina and muri. The variations of exine ornamentation on the surface and sulcus edge for the other species were in agreement with the performed sections classification. Moreover, the number of exine surface lumina for each species was also different and the least and the most number of lumina was counted in the subgenus Melanocrommyum. Our results also indicated that $A$. obliquum belong to section Oreiprason and subgenus Polyprason had no lumina in the exine surface. In the studied species in Iran, the exine surface ornamentation without lumina was observed in the subgenus Reticulatobulbosa in section Campanulata and also in the subgenus Polyprason in section Falcatifolia [11]. Therefore, the exine surface ornamentation without lumina can be defined as a useful morphological character in the subgenus Polyprason and its related sections. In flora of Pakistan $A$. rosenbachianum on section Megaloprason, $A$. schoenoprasum belongs to section Schoenoprasum and $A$. roylei in section Oreiprason were placed on $A$. roylei types based on the pollen grain morphology [14].

The dendrogram of the pollen characters analysis was in agreement with the taxonomical ranking and previous phylogram by [1] on these taxa in subgenus and section levels. The phylogram of the studied species were distinguished based on [1]. These authors had done the extensive phylogenetic analysis by molecular data (ITS nuclear marker and rps16 chloroplast marker) on Allium genus. The final dendrogram of our palynological investigation was in agreement with the obtained phylogram by [1]. According to the pollen dendrogram obtained from analysis by SEM observations in subgenus Melanocrommyum, $A$. fetisowii introduced as a sister group with the other species in this subgenus. In clade Melanocrommyum, $A$. fetisowii in section Longibidentata determined as the sister group of the remaining species of the subgenus Melanocrommyum based on the phylogenetic 
information of molecular markers [1]. $A$. schoenoprasum belongs to subgenus Cepa and section Schoenoprasum was different from the other species in SEM observation, although in the state of pollen grain apex was similar to $A$. fetisowii. The results also indicated that $A$. altissimum, $A$. backhousianum and $A$. karataviense species with similar size in lumina were placed in the subgenus Melanocrommyum. The palynological dendrogram in this study put the species $A$. altissimum and $A$. backhousianum from subgenus Melanocrommyum and in sections Procerallium and Acmepetala together. Moreover, according to the molecular studies, these two sections were put together [1].

\section{CONCLUSION}

The dendrogram of palynological analysis data in the related species was in parallel with the divisions of sections and subgenera taxonomical rank and the phylogram of phylogenetic studies. Also, our research on the genus Allium confirms some previous palynological research.

\section{ACKNOWLEDGEMENTS}

The authors are grateful from the Main Botanical Garden of Russian Academy of Sciences (MHA) for cooperation and provision the samples, Razi Metallurgical Institute, Tehran, Iran, for taking the SEM micrographs, cellular and molecular research center, Iran University of Medical Sciences, Tehran, Iran and interfaculty laboratory of the Lomonosov State University (Dr. Svetlana Polevova), Moscow, Russia for taking of TEM micrographs.

\section{COMPETING INTERESTS}

Authors have declared that no competing interests exist.

\section{REFERENCES}

1. Li QQ, Zhou SD, He XJ, Yu Y, Zhang YC, Wei $X Q$. Phylogeny and biogeography of Allium (Amaryllidaceae: Allieae) based on nuclear ribosomal internal transcribed spacer and chloroplast rps16 sequences, focusing on the inclusion of species endemic to China. Ann Bot. 1990;106: 709-33.

2. Özhatay N, Kocyigit M. Pollen morphology of Allium species (Lilliaceae) in European Turkey and around Istanbul. Phytol. 2009; 15(2):199-208.
3. Fritsch RM, Abbasi M. Taxonomic Review of Allium subg. Melanocrommyum in Iran, Germany, Leibniz-Institut fur Pflanzengenetik und Kulturpflanzenforschung Gatersleben, 2013.

4. Klaas M. Applications and impact of molecular markers on evolutionary and diversity studies in the genus Allium. Plant Breed. 1998;117:297-308.

5. Fritsch RM, Friesen N. Evolution, domestication and taxonomy. In: Rabinowitch, H. D. \& Currah L. (eds.): Allium crop science: recent advances,Wallingford, New York. 2002; 5-30.

6. Kosenjo VN, Kudryashova GL. Palynomorphology of the family Alliaceae, Bot. Zhurnal (st. Petersburg). 1995;80(6): 5-17.

7. Radulescu D. Recherches morphopalynologiques sur la famille Liliaceae, Acta Bot. Horti. Bucur. 1973;133-248.

8. Harley MM, Zavada MS. Pollen of the monocotyledons: Selecting characters for cladistic analysis. In: Monocots: Systematics and Evolution, K.L, Melbourne, Wilson and D.A Morrison (Eds). CSIRO. 2000;194-213.

9. Güler U, Pehlivan S. Pollen morphology of some species belonging to Codonoprasum and Allium sections of Allium (LiliaceaeAlliaceae) genus, Biologia. 2006;61(4): 449-55.

10. Neshati F, Fritsch RM, Zarre S. Pollen morphology of some Allium L. species (Alliaceae) from Iran. Plant Diversity and Evolution. 2009;127(4):433-451.

11. Namin HH, Mehrvarz SS, Zarre S, Fritsch RM. Pollen morphology of selected species of Allium (Alliaceae) distributed in Iran, Nordic J. Bot. 2009;27(1):54-60.

12. Özler H, Pehlivan S. Pollen morphology of Allium L. (Lilliaceae) taxa in Turkey, Bangladesh J. Bot. 2010;39(1):37-46.

13. Wronska-Pilarek $D$, Halbrither $H$, Krazyminska A, Rzyminska L, Bednorz J. Bocianowskij J. Pollen morphology of selected European species of the genus Allium L. (Alliaceae), Acta Sci. Pol. Hortorum Cultus. 2016;15(4):65-84.

14. Perveen A, Qaiser M. Pollen flora of Pakistan-Ixviii. Alliaceae, Pak. J. Bot. 2015;47(1):263-68.

15. Erdtman G. The acetolysis technique: A revised description, Svensk Botanisk Tidskrift. 1960;54:561-64. 
16. Reynalds ES. The use of lead citrate at high $\mathrm{pH}$ as an electron opaque stain in electron microscopy. Journal of Cell Biology. 1963;17:208-212.

17. Weakley BS. A Beginner's handbook in biological electron microscopy. Churchill Livingstone, Edinburg. 1972;252.

18. Tokarev P. Morphology and ultrastructure of pollen grain. Moscow, KMK Sci, Press Ltd.; 2003.

19. Punt W, Hoen PP, Blackmore S, Nilsson $S$, Le Thomas A. Glossary of pollen and spore terminology, Rev. Palaeobot. Palynol. 2007;143:1-81.
20. Hesse $M$, Zetter $R$, Halbritter $H$, Weber M, Buchner R, Froschradivo A, Ulrich S. Pollen Terminology (An illustrated handbook). Vienna, Springer; 2009.

21. Rohlf FJ. NTSYS-PC: Numerical Taxonomy and Multivariate Analysis System. Exeter Software, Setauket, NY, USA; 1993.

22. Bareemizadeh F, Maassoumi SM, Ghasempour H, Karimi N. Pollen morphology of the genus Allium in comparison with genus Calochortus of order Liliales, Int. J. Biosci. 2014;4(12): 237-43.

(c) 2019 Heidarian et al.; This is an Open Access article distributed under the terms of the Creative Commons Attribution License (http://creativecommons.org/licenses/by/4.0), which permits unrestricted use, distribution, and reproduction in any medium, provided the original work is properly cited.

Peer-review history:

The peer review history for this paper can be accessed here: http://www.sdiarticle3.com/review-history/50410 